\title{
Initiative or Passive: Self-Identity's Change of Chinese American Females in Interracial Marriage
}

\author{
Yuquan Liu ${ }^{1, *, \dagger}$, Ruixian Sheng ${ }^{2, *, \dagger}$, Xiaoli Xiong ${ }^{3, *, \dagger}$ \\ ${ }^{1}$ China Academy of Art, No.218, Nanshan Road, Hangzhou, Zhejiang, 310000, China \\ ${ }^{2}$ Wuhan University of Bioengineering, Wuhan, Hubei, 430415, China \\ ${ }^{3}$ University of British Columbia, British Columbia, V6T 1Z4, Canada \\ ${ }^{*}$ Corresponding author.Email: ${ }^{1} 15157705137 @ 139 . c o m ;{ }^{2}$ Rs6149@nyu.edu, ${ }^{3} X x 101011 @ s t u d e n t . u b c . c a$ \\ These authors contribute equally.
}

\begin{abstract}
The racial topic is always the hot spot among the American public. As the significant minority group with special background in America, Chinese American females in interracial marriage are worthwhile to be focused on. In this research, we contribute to figuring out the reasons behind the self-identity change of Chinese American women from aspects of history, politics and economics. Through data research and literature analysis, the paper demonstrates the real position of Chinese American women in interracial marriage. It indicates that the necessity of adapting to American society and the chasing for self-worth facilitate self-identity changes. This finding also shows that higher status in society is what Chinese American females are eager for, so interracial marriage becomes an ideal way to obtain what they desire. It provides a fresh point to survey the situation of Chinese immigrants in America, especially leading people to pay more attention to Chinese American women's living conditions and psychology in interracial marriage.
\end{abstract}

Keywords: Chinese American, female, self-identity, interracial marriage, immigration.

\section{INTRODUCTION}

Immigrants are an indispensable proportion of the United States' population. People from different backgrounds gather together, living in a new environment. Such surrounding change would inevitably reshape their consciousness and perception of society. This change will also affect their self-identity and weltanschauung. The paper aimed to analyze relevant academic resources to find a reasonable explanation for how Chinese immigrants' identities change after immigrating to the United States and historical and social influences. The early history of Chinese immigrants were primarily lower-class males who escaped from China for various reasons like natural disasters, political oppression and class struggle. These populations were mainly located in the United States near ocean cities which later formed concentrations of Chinese immigrants. They were still strongly bond their identity with China or in another world, with the social relationship in China. In contemporary Chinese immigration to the United States, there is a noticeable shift in the purpose for such behavior. The majority group seeking an opportunity has changed; more and more Chinese women immigrate to the United States. Their purpose and desire for such action were similar to the early Chinese immigrant looking for a new start. The motivation for them has changed into similar factors like class, career and marriage.

This paper will provide a clearer sight to understand how Chinese immigrants in the United States changed their identity and how their relationship with China was shaped during this process. Studying the new pattern would shed light on understanding how Chinese immigration has changed and possibly predict future immigration tendencies.

\section{EARLY CHINESE IMMIGRANTS IN UNITED STATE}

The situation of early Chinese immigrants in the United States was frustrating. It was clear that Chinese immigrants were treated as aliens or savagery by looking back at a series of laws and strategies. They were restricted from entering America, especially the women, not to mention interracial marriage. Between 1880 to 
1954, most states did not allow marriage between "white" and a "Chinese," "Japanese," or "Mongolian". But these immigrants evaded this law by obtaining licenses in states that did not restrict such marriage. Surprisingly, most of these marriages were between "Asian" men and "White" women due to the extremely imbalanced gender ratio among the Asian population during that period [1].

Money is the main motivation for early Chinese immigrants. After discovering gold in the western United States, many Chinese immigrants leave their homeland and seek new opportunities in the western United States. The city of San Francisco, in Mandarin meaning, is referred to as the old gold mountain. Chinese labor was considered crucial during the $1850 \mathrm{~s}$. It was stated that "Opposition to exclusion occurred in California in the early 1850s because Chinese immigrants were important taxpayers when both the state and localities were experiencing major financial difficulties" [2]. Continuing with this idea that Chinese immigrants who are mostly male contributed to these major financial crises. It would be reasonable that Chinese immigrants had strong voices in society. However, similar to how western colonialism affects the African population, it again, because of similar economic reasons. Potentially because both the municipal and state governments lacked funding to support public services like schools during that period. Considering that most early Chinese immigrants work as miners. It could infer that most of them were young males. They would likely consume a small number of public services while generating more benefits like taxes towards the local government. Thus, despite the demands on excluding Chinese immigrants from crowds (mostly local miners) and state, it was not feasible until the financial shortage recovered. After recovering from financial storage, the government passed laws to restrict the amount of Chinese labor by increasing tax and cost for new coming Chinese immigrants.

Many Asian scholars thought that most of these marriages were between white men and Asian women, but this characterization was incorrect. In the earlier period, the primary form of Asian-white marriage was with Asian men and white women. As people estimate, such intimate relationships happen across all social classes rather than only in the lower class. However, even though most Asian-white marriages were between Asian men and white women, Asian women and white men have more privileges. The law system that supports white supremacy leads to regulations like only Asian women who married white men could be qualified as legal immigrants while Asian men who married white women cannot [3]. During world war II (WWII), these Asian husbands were seen as Enemy aliens and were sent to internment. For white husbands, they could have their children and Asian wives safely ensconced within their patriarchal household.

Even before WWI, there were regulations against Asians, particularly Chinese immigrants. All of these acts as incentives resulted in 1870 the gender ratio between men and women is 13:1 [4]. By the end of 2020, data from the American Immigration Council showed that the male and female ratio between Chinese immigrants is 9:12 [5]. Obviously, the purpose of immigration and participants has changed due to the new political and social environment.

\section{INTERRACIAL MARRIAGE MOTIVATION ANALYSIS}

The initial interracial marriage with a white male can give oneself a legalized identity, and a legal identity can thus help a person better integrate into this society. This phenomenon has continued into today's society, and its newest expression could be to improve one's social status through marriage. We do not classify it immediately but analyze marriage as a whole closely related to the economy. There is a famous hypothesis called the "economic dependence hypothesis." Sweeney interprets this term in her article that "women with good prospects in the labor market will be less likely to marry than will women with relatively poor prospects." This quote is significant because it explains that marriage can be more necessary for lower-class people. That is to say; marriage can bring economics. No matter which country a person comes from, they all live in societies, so it is inevitable to avoid social stratification. Members of a given society are categorized and divided by unequal wealth, power, and prestige. Socio-economic status (SES) is a term used by sociologists for the social class stratification method practiced primarily in capitalist societies. 


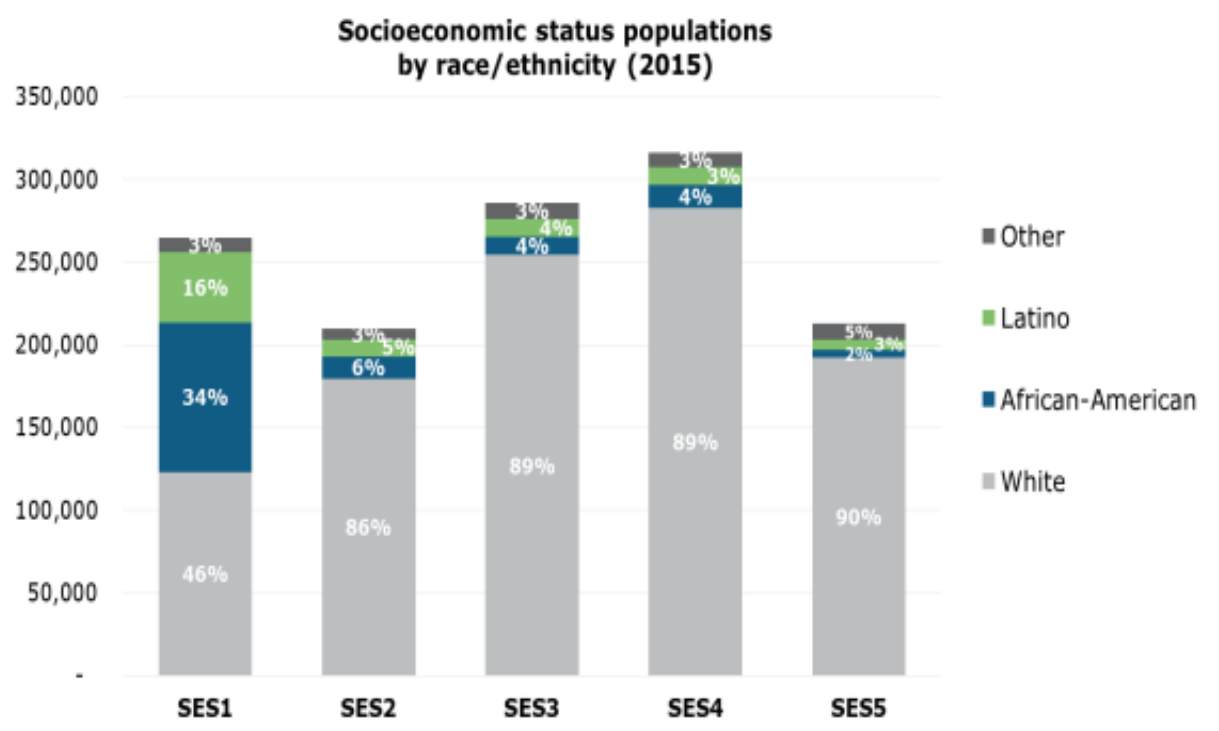

Figure 1 Socio-economic status populations by race/ethnicity (2015)

Figure 1 interprets the structure of the SES in the United States. From ranking 1-5, level 5 represents the highest average income and socio-economic status. In the higher SES levels, white people account for more. Therefore, the social status of white people cannot be ignored.

Many Chinese women who first immigrated to the United States gather in the working class or the middle class. Although they have economically independent lives, it is difficult for them to elevate their social classes. The reason is that social class has stability, which means that a person's future class is likely to be consistent with the class of the birth family. One of the most distinctive features of a family's social class is education. Elite families are more likely to provide elite education to future generations, such as the opportunity to study at private schools, attend tutorial classes, exploring many hobbies. They can also provide nonacademic support, such as extensive social Networks with elite friends. In other words, it is neither easy for middle-class children to descend to the proletariat nor is it easy to rise to the upper class through their self-efforts.

Even before World War Two (WWI), there were regulations against Asians, particularly Chinese immigrants. All of these acts as incentives resulted in 1870 the gender ratio between men and women is 13:1 [6]. By the end of 2020, data from the American Immigration Council showed that the male and female ratio between Chinese immigrants is 9:12 [7]. It was obvious that the purpose of immigration and participation has changed because of status.

For example, Chinese nurses in the United States are one of the fastest-growing groups coming to the United States [8]. An investigation has shown that the demand for immigration depends on their length of stay. Factors that may impact such demand were divided into six different categories [9]. Loss, novelty, occupation, language, subordination, and discrimination. Chinese immigrant has scored highest in the discrimination section. It demonstrated that they have a harder time struggling with their identity [10]. Even after living in the United States for over the years, they still identified themselves as second-class citizens and were not respected by Americans [11]. The fear of potential racism and isolation, accompanied by a feeling of not being at home. As a deviant in another country, this affects their identity significantly. This result demonstrates that difficulties exist and continue to affect these Chinese immigrants and their relationship with their identification with China and the United States.

\section{THE EVOLUTION OF INTERRACIAL MARRIAGE STATUS}

The changes in Chinese immigrant women's identity are worthwhile to be focused on. Since the sources about Chinese immigrant women in the 19th century are a minority, before 1954, most states of America did not allow marriage between white people and Chinese, so it is reckless to tell what the changes were. Most of the sources related to that period were about the roles and status of Chinese immigrant women whose husbands were also Chinese immigrants [12]. At first, Chinese immigrant women were restricted from entering the US. Those who finally immigrated to America were surrounded by discrimination and prejudices. Many fell into whores and were regarded as stains of order in society [13]. Women who settled down with their husbands gradually became essential roles in the families because they were far away from their relatives and friends in China and were nuclear ones. They found they were freed from the authority of their mothers-in-law, which gave them a better feeling of being a female. In that case, which lacks examples about Chinese immigrant women in an interracial marriage, we can 
only argue that the identities of Chinese women in immigrant families were improved. The instances of marriage between Chinese men and white women were the most, for the population of Chinese immigrant men was much larger.

In the 40 s of the 20th centuries, the situation began to alter as America released more tolerant policies and laws aimed at immigrants. More Chinese immigrant women entered America. Compared with Asian males, Asian females were more likely to have an interracial marriage at that period. Asian men with white wives were seen as unqualified ones, but white men with Asian wives could live safely in their residents [14]. In the second half of the 20th century, interracial marriage between white and Asians increased overall

The positive changes in Chinese women's identity are also outstanding, especially in the late 20th century and nowadays. For numbers of Chinese immigrant women, America does better in gender equality and social opportunities, so settling down in the US through interracial marriage is ideal for some females [15]. Living with an interracial relationship offers them a sense of self-satisfaction and confidence. The awareness of getting higher rights and being independent gets stronger when they are in America, and they appeal to have a fiercer willingness to insist on freedom. Out of the expectancy of many Chinese people, American culture is not that outgoing in sexuality, and similarities exist between Chinese culture and American culture [16]. Therefore, it is not too difficult for some Chinese immigrant women to immerse into American society.

Whether Chinese immigrant women are satisfied or disappointed, they can hardly return to their original cultural backgrounds. Searching for acknowledgment from local society forces them to change their selfidentity [17].

As Chung pointed out in the book "In Pursuit of Gold: Chinese American Miners and Merchants in the American West," the major motivation is the new opportunity and escape from intense social problems in China [18]. Serious economic recessions happened in 19th century China due to natural disasters, socioeconomic issues and political chaos. The majority population affected by these issues are farmers. The overexploitation from landowners, natural disasters, and banditry eventually result in moving abroad, appearing to be their only possible solution for them to survive. This group of immigration became the largest proportion of early Chinese immigrants in the United States.

\section{FEMALE IDENTITY RESHAPING IN INTERRACIAL MARRIAGE}

As mentioned previously, the majority proportion of early Chinese immigrants depend on intense labor like mining. The living condition for them is, however, still strongly connected to their social relationship in China. An example of this from Chung is that when the new immigrants arrive in the US, men from the same original district or their family association meet and help them find housing, career, and living necessities. Compared to contemporary immigrants, these early immigrants were tightened together to their home country. Since most of these early immigrants were originally working as farmers, very few could read or write a letter. Thus, they heavily rely on Chinese merchants who sell them goods to keep communicating with their families.

These Chinese women have entered a whole new social setting with their marriage to white Americans. Together with the family they created, they have formed different meaningful social connections that are more supportive to gain respect from others and a sense of achievement. The new social settings for the Chines women can be roughly divided into two occasions: the professional women in the workplace and the wife and mother in the family.

First, the marriage granted the Chinese immigrant's legal status in the US as a direct outcome. Long-term staying and working authorization are important benefits immigrants can get from the new statutes [19]. So, they have access to more secured jobs with a better salary. And the women in stable and higher-end jobs can form healthier social connections.

Usually, the jobs are more rewarding and finishing the work tasks helps build up the women's sense of achievement. At the workplace, colleagues tend to be more respectful to each other and recognize their values [20]. The secured jobs shaped part of their self-esteem. So, the American identity is attractive for these Chinese women as professionals.

Although many Chinese immigrants have gained various authorizations outside the marriage, they usually enjoyed more rights after entering the marriage with white Americans. They shared an experience with the high-skilled female immigrants in general that they had to take on "gigs" in the early stage of immigration. Usually, the situation changed after they started a family [21].

As the non-zero-sum mobility theory mentioned, marriage naturally fills the social vacancies without facing many conflicts [22]. In marriage, Chinese women can have less well-paid jobs than they preferred [23]. They do not have to be aggressive and competitive as those struggling with an H1B working visa. So, they also mentioned work-life balance as an advantage that the US offered over China.

The Chinese women have long made a name as good wives and strict mothers in stereotypes and reality. The community that women moved into after the marriage is safer and friendlier for starting a family life. More importantly, Chinese women in marriage attach great 
value to children's education. So, they prefer living in communities with top schools, which only the good communities can provide [24]. Such communities offer them supportive social connections. Together with their willingness to blend in the community as responsible neighbors for the sake of their family, it became part of their life to attend community service and socialize with other residents [25].

And the neighbors can recognize the "positive images" of these Chinese women as good "Asian wives" and "tiger moms" [26]. They are accepted into the community as a major member of their core family, usually considered white Americans.

\section{CONCLUSION}

Generally speaking, the article shows the historical backgrounds behind the identity changes of Chinese immigrant women in an interracial marriage and what exactly the changes are. In the beginning, most examples were marriages between white women and Chinese immigrant men due to an extremely imbalanced gender ratio. Because at that period, most Chinese immigrants were males who searched for wealth in America. Yet, the Asian women and white men couple could live a better life on white supremacy. At the same time, interracial marriage with a white male could bring one a legal identity and economics in America. So Chinese women who immigrate to America are apt to marry a white man. Now the male and female ratio between Chinese immigrants is contrary to the situation in 1870 , probably because of the privileges related to white. But for Chinese immigrant families early, the roles of Chinese immigrant women became more fundamental since they were isolated in America, and women in families could offer strong supports. As a result, these women felt they were more independent than in China. As interracial marriage with a white male can provide many benefits, Chinese immigrant women were intended to marry white men. Interracial marriage would give them a feeling of satisfaction with the advancement of socio-economic status while also bringing them loneliness and selfdoubt, which depends on divided situations. The paper provides the deep reasons for interracial marriage that can also explain what changes the identity of Chinese immigrant women in interracial marriage.

Marrying a white male offers more opportunities and higher status, and those Chinese immigrant women could self-declare as American. The blurred color line in the US is another main reason Chinese immigrant women can face fewer limitations than before. An obvious phenomenon is that most Chinese immigrant women will not choose to go back, for Chinese society commonly holds negative views about them and earns a more wellcontent life in America than they were in China.
It is a new way for us to review females, Chinese immigrants and interracial marriage. More importantly, a window for us to observe American society is open.

\section{REFERENCES}

[1] American Immigration Council. (2020). Immigrant Women and Girls in the United States- A Portrait of Demographic Diversity.

[2] Kanazawa, M. (2005). Immigration, Exclusion, and taxation: Anti-Chinese legislation in gold rush California. The Journal of Economic History, 65(3), 779-805.

DOI: https://doi.org/10.1017/S0022050705000288

[3] Kwon, E. (2011). Interracial marriages among Asian Americans in the US west, 1880-1954 (Order No. 3585246). Available from ProQuest Dissertations \& Theses Global. (1508568951).

[4] Catherine, L. (2010). "Where the Danger lies": Race, Gender, and Chinese and Japanese Exclusion in the United States, 1870-1924. Sociological Forum, 25(2), 248-271. DOI: https://doi.org/10.1111/j.1573-7861.2010.01175.x

[5] Amy, M. Mary, Q. Katie, C. Joyce, F. (2010). Demands of immigration among Chinese immigrant nurses. International Journal of nursing practice, 16(5). 443-453. DOI: https://doi.org/10.1111/j.1440-172X.2010.01868.x

[6] Chung, S.F. (2011). In Pursuit of Gold: Chinese American Miners and Merchants in the American West. Champaign: University of Illinois Press

[7] American Immigration Council. (2020). Immigrant Women and Girls in the United States- A Portrait of Demographic Diversity.

[8] Kanazawa, M. (2005). Immigration, Exclusion, and taxation: Anti-Chinese legislation in gold rush California. The Journal of Economic History, 65(3), 779-805.

[9] Kwon, E. (2011). Interracial marriages among Asian Americans in the US west, 1880-1954 (Order No. 3585246). Available from ProQuest Dissertations \& Theses Global. (1508568951).

[10] Catherine, L. (2010). "Where the Danger lies": Race, Gender, and Chinese and Japanese Exclusion in the United States, 1870-1924. Sociological Forum, 25(2), 248-271. DOI: https://doi.org/10.1111/j.1573-7861.2010.01175

[11] Amy, M. Mary, Q. Katie, C. Joyce, F. (2010). Demands of immigration among Chinese immigrant nurses. International Journal of nursing practice, 
16(5). $\quad 443-453 . \quad$ DOI: https://doi.org/10.1111/j.1440-172X.2010.01868.x

[12] Sweeney, Megan. M. (2002) "Two Decades of Family Change: The Shifting Economic Foundations of Marriage" American Sociological Review. American Sociological Association 67(1), 132-147. DOI: https://doi.org/10.2307/3088937

[13] Lee, E. (2010). "The Chinese are coming. How can we stop them? Chinese exclusion and origins of American gatekeeping" in Asian American Studies Now: A Critical Reader (pp. 143-167). Rutgers University Press.

[14] Kwon, E. (2011). Interracial marriages among Asian Americans in the US west, 1880-1954 (Order No. 3585246). Available from ProQuest Dissertations \& Theses Global. (1508568951).

[15] Gu, Y. (2016). Chinese Dreams? American Dreams? The lives of Chinese Women Scientists and Engineers in the United States. Sense Publishers.

[16] Wang, L. (2014). Communication Barriers in Interracial Marriage between American and Chinese which due to Value Conflicts. Heilong River Science, 5(12), 169-191.

[17] Zhang, P. (2008). A Study on Overseas Chinese Women Writers 'Autobiography. Journal of Chongqing Three Gorges University, 24(113), 7678.

[18] Chung, S.F. (2011). In Pursuit of Gold: Chinese American Miners and Merchants in the American
West. Champaign: University of Illinois Press.

[19] Hayes, H. (2001). US Immigration Policy and the Undocumented: Ambivalent Laws, Furtive Lives. Praeger Publishers.

[20] Gu, DY (2016). Chinese Dreams? American Dreams? The Lives of Chinese Women Scientists and Engineers in the United States. Rotterdam: Sense Publishers.

[21] Colakoglu, S. Dilek, G. Arman, G. (2018). HighSkilled female immigrants: career strategies and experiences. Journal of Global Mobility. 6(3/4), 258-284.

[22] Alba, R. (2009). Blurring the Color Line: The New Chance for a More Integrated America. Cambridge: Harvard University Press.

[23] Suto, M. (2008). Compromised careers: The Occupational Transition of Immigration and Resettlement. Work. 32(4). 417-429.

[24] Chang, B.B. (2017) Asian Americans and Education. Oxford Research Encyclopedia of Education. education.oxfordre.com.

[25] Ecklund, E.H. Park, J.Z. (2005). Asian American Community Participation and Religion: Civic Model Minorities? Journal of Asian American Studies. 8(1), 1-21.

[26] Wang. S, The Tiger Mom Stereotypes of Chinese Parenting in the United States. Applied Psychology Opus. https://wp.nyu.edu/steinhardtappsych_opus/the-tiger-mom-stereotypes-ofchinese-parenting-in-the-united-states/. 